\title{
AC conductivity and battery application of polyethylene oxide/PANI/sodium chlorate composites
}

\author{
Kunteppa. $\mathbf{H}^{\mathbf{1}}$, Ameena Parveen ${ }^{2}$, H. G. Harish Kumar ${ }^{3}$, Aashis. S. Roy ${ }^{4^{\star}}$ \\ ${ }^{1}$ Department of Physics, Govt. Pre University College, Raichur, Karnataka, India \\ ${ }^{2}$ Department of Physics, Govt. First Grade College, Gurmitkal, Yadgir, Karnataka, India \\ ${ }^{3}$ Department of Physics, R.V. College of Engineering, Bangalore 566059, India \\ ${ }^{4}$ Department of Materials Science, Gulbarga University, Gulbarga, Karnataka India
}

*Corresponding author. E-mail: aashis_roy@rediffmail.com

Received: 16 March 2013, Revised: 15 May 2013 and Accepted: 17 May 2013

\section{ABSTRACT}

Polymer electrolytes based on polyethylene oxide complexes with conducting polyaniline (PANI) and a salt of sodium chlorate has been prepared in different weight percentage ratios. The complexation is confirmed by FTIR spectroscopy and morphology study by employing SEM. AC conductivity measurements are carried out by using LCR Q meter at room temperature. Electrochemical cell parameters for battery applications at room temperature are also determined. The composites PP5, N3 and N4 show good conductivity which is due to ionic polarization and electrode polarization. Among all these composites N3 shows highest conductivity which is also well understood through the SEM studies. PP5 shows more conductivity than all the other composites except N3 as because PANI when mixed with PEO gives more feasibility of matrix's for fast mobility of ions through it easily. The samples are fabricated for battery applications in configuration of $\mathrm{Na}:(\mathrm{PEO}: \mathrm{PANI}: \mathrm{NaClO} 4):\left(\mathrm{I}_{2}+\mathrm{C}+\right.$ sample) and their experimental data are measured using the Wagner polarization technique.

Copyright @ 2013 VBRI press.

Keywords: Polyelectrolyte; AC conductivity; electrochemical cell; battery.
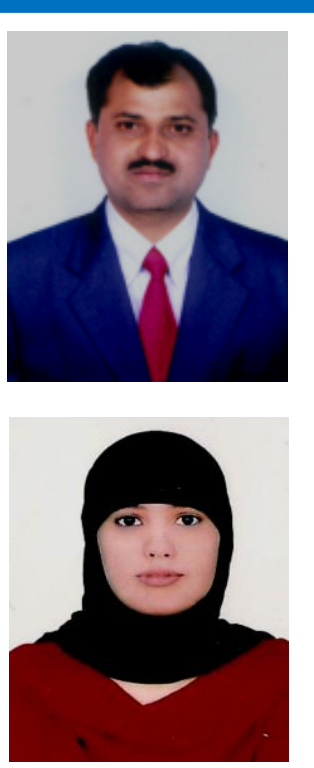

Ameena Parveen completed M.Sc and Ph.D in physics, Gulbarga University, Gulbarga, India. Presently working as Assistant Professor in Physics, Govt First Grade College Guirmitkal, Yadgir, India. Research interest is Synthesis of Nanomaterials, Porous Metal Oxide, Conducting Polymer Nanocomposites, Chemical Sensors, Microwave Studies, Modulous Spectroscopy and Fabrication of Organic Photovoltaic cells.

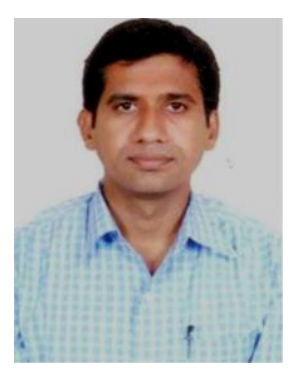

H. G. Harish Kumar got his Ph.D from Gulbarga University Gulbarga and currently working a Assistant Professor in Physics, R.V. College of Engineering, Bangalore. His research interest is to preparation of thin film for packaging, Dielectric studies of nanomaterials, Microwave studies of ferrite materials etc.

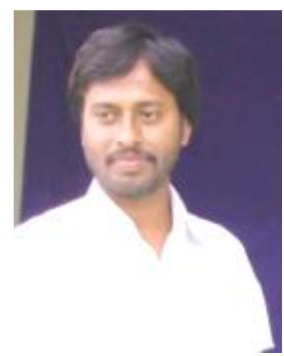

Aashis. S. Roy got his M.Sc and Ph.D degree in Materials Science from Gulbarga University, Gulbarga, Karnataka, India. He is working as Research Associate in Department of Materials Engineering, Indian Institute of Science, Bangalore, India. Research interest is Humidity Gas Sensors Applications, Development of Conducting Polymer Ceramic Nanocomposites and to Fabricate the Gas Sensors and Organic Photovoltaic Devices. 


\section{Introduction}

Polymer electrolytes based on polyethylene oxide (PEO) salt complexes are of great interests due to their theoretical as well as practical importance for the development of Solid State Batteries, Fuel cell, Smart Windows, Sensors and Electrochromic Display Devices [1-4]. The main advantages of polymer electrolytes are their favorable mechanical properties, ease of combination with salts or with some polymers and also an ability to form proper electrode- electrode contacts. The interest in these electrolytes arose in the studies of materials based on alkali metal salts complexed with polyethylene oxide that were conducted by Wright and coworkers $[\mathbf{5 , 6}]$ and Armand and co-workers [7, 8] in the 1970s.

Polyethylene oxide (PEO) in particular is an exceptional polymer which dissolves with concentrations of a wide variety of salts to form polymer electrolytes [9].Complexes of PEO with $\mathrm{LiBF}_{4}, \mathrm{LiPF}_{4}$, and $\mathrm{Li}\left(\mathrm{C}_{6} \mathrm{H}_{5}\right)$ [10], $\mathrm{LiSCN}[11], \mathrm{LiSO}_{3} \mathrm{CF}_{3}$ and $\mathrm{LiClO}_{4}$ [12], NaSCN [13], $\mathrm{NaPF}_{6}[14], \mathrm{NaXF}_{4}$ and $\mathrm{KYF}_{4}$ [15], and $\mathrm{PEO}+\mathrm{NH}_{4}+\mathrm{Al}_{2} \mathrm{O}_{3}$ [16] have been examined. Recently, new classes of PEO/PANI composites have been reported by Sixou et al. [17]. Recent research trends in the field of rechargeable lithium batteries are directed towards the development of cells with high energy density and high-power density [18]. To achieve high amount of energy stored in a given mass or volume, it is usually desirable that the number of available charge carriers per mass or volume unit must be as high as possible. The capacity for energy storage in a rechargeable lithium cell is mainly dependent on cathode materials.

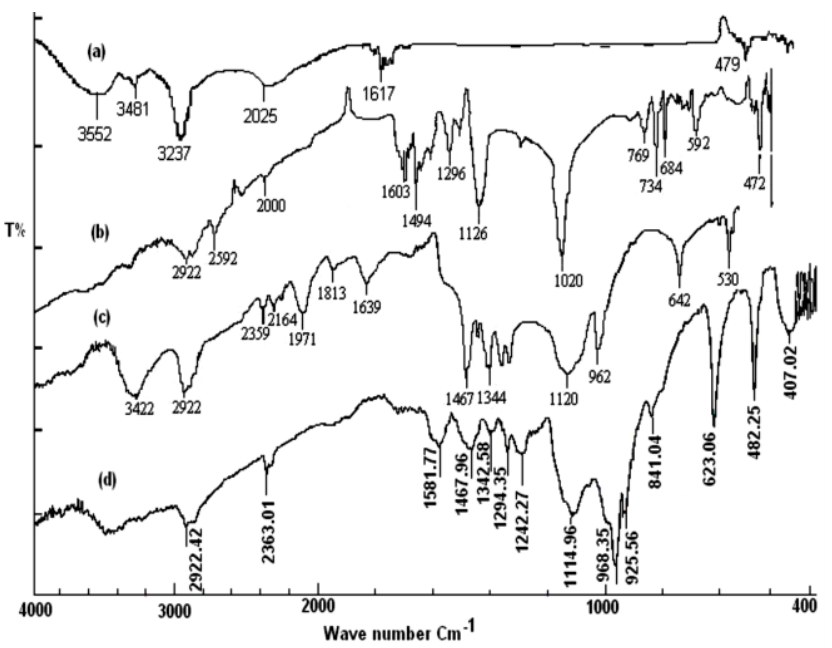

Fig. 1. FTIR spectrum of (a) $\mathrm{NaClO}_{4}$ (b) PANI (c) PEO and (d) PEO: PANI: $\mathrm{NaClO}_{4}(50: 10: 40)$.

The most studied cathode materials for lithium batteries are crystalline cobalt, manganese and nickel-based oxides [19]. Efforts have been made in continuity to improve the capacity of cathode materials and more attempts to synthesize transition metal oxides with an amorphous nature and high surface area such as the xerogel and aerogel forms which have been made from $\mathrm{V}_{2} \mathrm{O}_{5}$ and $\mathrm{MnO}_{2}[20,21]$. Hybridization of the layered inorganic cathode materials with electrochemically active organic polymers is another interesting approach to improve the capacity for electrochemical lithium insertion. Intercalating organic molecules into the layered inorganic host materials can produce inorganic-organic hybrid materials such as $\mathrm{V}_{2} \mathrm{O}_{5}$ with polyaniline (PANI), poly (ethylene glycol) (PEG), polypyrole (PPY) and poly (ethylene oxide) (PEO) [22 - 24].

In this present work authors have carried out the synthesis, characterization, DC conductivity and battery applications. The ac conductivity shows that $\mathrm{N} 3$ has high conductivity among all composites. It is observed that N3 composites have high current compare to other composites due to more feasibility for ion moments. Therefore, PEO: PANI and PEO: PANI: $\mathrm{X}\left(\mathrm{NaClO}_{4}\right)$ composites are possible better candidates for solid state batteries [25].

\section{Experimental}

\section{Materials}

Polyethylene oxide (relative molecular mass of $5 \times 10^{5}$ ) was obtained from Shanghai Research Institute of Chemicals, China and dried under vacuum at $50{ }^{\circ} \mathrm{C}$ for 24 $\mathrm{h}$ before use. Sodium perchlorate $\left(\mathrm{NaClO}_{4}\right)$ obtained was analytical grade from Sigma Aldrich and dried under vacuum at $120{ }^{\circ} \mathrm{C}$ for $24 \mathrm{~h}$ to remove water from the crystal and polyaniline was prepared in our laboratory by standard chemical oxidation method [26].

\section{Preparation of composites}

PEO: PANI, PEO: $\mathrm{NaClO}_{4}$ and PEO: PANI: $\mathrm{NaClO}_{4}$ composites were prepared by stirring in anhydrous acetonitrile for 5-6 hrs to form homogeneous gels at different weight percentages (50:10:40 (N1), 50:20:30 (N2), 50:30:20 (N3) and 50:40:10 (N4) respectively). The gels were poured into glass plates in a dry room fume hood and left for $12 \mathrm{~h}$ to remove the majority of the acetonitrile. The composites so obtained from the above procedure were than further dried at $60{ }^{\circ} \mathrm{C}$ under vacuum for $24 \mathrm{~h}$. The composites were stored in the dry room at $22{ }^{\circ} \mathrm{C}$ for several weeks prior to characterization. The FTIR spectra of the samples were recorded on a Perkin Elmer 1600 spectrophotometer in $\mathrm{KBr}$ medium and SEM has been carried out for PEO: PANI: $\mathrm{NaClO}_{4}$ composites on Phillips XL 30 ESEM.

\section{Results and discussion}

Fig. 1(a) shows that the FTIR spectra of pure pristine sodium chlorate $\left(\mathrm{NaClO}_{4}\right)$ and it has predominant peaks at the wave number of $3552 \mathrm{~cm}^{-1}$ which corresponds to water absorbed by the salts, $3481 \mathrm{~cm}^{-1}$ and $3237 \mathrm{~cm}^{-1}$ corresponds to $\mathrm{O}-\mathrm{H}$ vibration and is formed at higher frequency due to splitting of water molecules, $2025 \mathrm{~cm}^{-1}$ corresponds to $\mathrm{Na}^{+}$ ions, $1617 \mathrm{~cm}^{-1}$ are due to chlorate $\left(\mathrm{ClO}_{4}^{-}\right)$ions.

Fig. 1(b) shows the FTIR spectra of pure polyaniline .The formation of polyaniline is confirmed by noticing the predominant peaks at the wave numbers of $1603 \mathrm{~cm}^{-1}$ corresponding to $\mathrm{C}=\mathrm{C}$ stretching of quinine ring, $1494 \mathrm{~cm}^{-1}$ for $\mathrm{C}=\mathrm{C}$ stretching of benzenoid ring, $1296 \mathrm{~cm}^{-1}$ for $\mathrm{C}-\mathrm{N}$ stretching, $1126 \mathrm{~cm}^{-1}$ due to $\mathrm{C}-\mathrm{O}-\mathrm{C}$ stretching of excess oxidant, $1020 \mathrm{~cm}^{-1}$ for S-O vibration, $769 \mathrm{~cm}^{-1}$ and 
$734 \mathrm{~cm}^{-1}$ for $\mathrm{C}-\mathrm{H}$ vibration of Para coupling benzenoid and benzene rings, $\mathrm{C}-\mathrm{H}$ bending is at $684 \mathrm{~cm}^{-1}, 592 \mathrm{~cm}^{-1}$ is corresponds to aromatic ring and $472 \mathrm{~cm}^{-1}$ is stretching at out of the plane.

Fig. 1(c) shows the spectra of pure polyethylene oxide. In pure PEO spectrum a large broad band appears centered at $3442 \mathrm{~cm}^{-1}$ which is due to the hydration of PEO which confirms that PEO is highly hydrophilic and gets hydrated. Thus pure PEO shows a large broad band of $\mathrm{CH}_{2}$ stretching's between 2950 and $2840 \mathrm{~cm}^{-1}$. However the band splits into two at $2922 \mathrm{~cm}^{-1}$ and $2359 \mathrm{~cm}^{-1}$ corresponding to asymmetric $\mathrm{CH}_{2}$ stretching $\left(\mathrm{n}\left(\mathrm{CH}_{2}\right) \mathrm{a}\right)$ and symmetric $\mathrm{CH}_{2}$ stretching $\left(\mathrm{n}\left(\mathrm{CH}_{2}\right) \mathrm{s}\right)$ respectively. It is also been observed that $\mathrm{CH}_{2}$ vibrational modes appear in PEO at $1467 \mathrm{~cm}^{-1}$ which corresponds to asymmetric $\mathrm{CH}_{2}$ bending $\left(\mathrm{d}\left(\mathrm{CH}_{2}\right) \mathrm{a}\right)$ and $1344 \mathrm{~cm}^{-1}$ which corresponds to symmetric $\mathrm{CH}_{2}$ wagging and some $\mathrm{C}-\mathrm{C}$ stretching $\left(\mathrm{w}\left(\mathrm{CH}_{2}\right) \mathrm{s}+\mathrm{n}(\mathrm{CC})\right)$ [27].

Fig. 1(d) shows PEO: PANI: $\mathrm{NaClO}_{4}$ (50:10:40) composites spectra. Observed peaks that appeared in spectrum are $2922.42 \mathrm{~cm}^{-1}, 2363.01 \mathrm{~cm}^{-1}, 1581.77 \mathrm{~cm}^{-1}$, $1467.96 \mathrm{~cm}^{-1}, 1342.58 \mathrm{~cm}^{-1}, 1294.35 \mathrm{~cm}^{-1}, 1242.27 \mathrm{~cm}^{-1}$, $1114.96 \mathrm{~cm}^{-1}, 968.35 \mathrm{~cm}^{-1}, 925.56 \mathrm{~cm}^{-1}, 841.04 \mathrm{~cm}^{-1}$, $623.06 \mathrm{~cm}^{-1}, 482.25 \mathrm{~cm}^{-1}, 407.02 \mathrm{~cm}^{-1}$. It is also observed that the intercalation of $\mathrm{NaClO}_{4}$ within PANI shows similar type of effect on PEO structure and in return on PEO crystallinity. The wave number found at $3552 \mathrm{~cm}^{-1}$ is absent in the composites and this is due to the interaction between the ether oxygen of PEO segments and the free O$\mathrm{H}$ groups of $\mathrm{NaClO}_{4}$ via hydrogen bonding. C-H stretching band appears at $2922.42 \mathrm{~cm}^{-1}$ which is slightly shifted to the higher frequencies which clearly indicates that there is strong interaction between PANI and PEO. This was further confirmed as the intensity of the band of $(\mathrm{n}(\mathrm{C}-\mathrm{O})$ at $1603 \mathrm{~cm}^{-1}$ for pure PANI and $1344 \mathrm{~cm}^{-1}$ in pure PEO respectively are shifted towards lower frequency in PEO: PANI: $\mathrm{NaClO}_{4}$ composites and the band of $(\mathrm{n}(\mathrm{O}-\mathrm{H})$ at 1581 $\mathrm{cm}^{-1}$ in PANI and $1342.58 \mathrm{~cm}^{-1}$ in PEO are intense. It is understood that $\mathrm{PEO}$ interacts not only with free $-\mathrm{OH}$ of $\mathrm{NaClO}_{4}$ but also it has well interaction with the interlayer cations in a similar manner to form conventional PEO salt complexes. The predominant peaks appeared in composites at $2922.42 \mathrm{~cm}^{-1}, 2363.01 \mathrm{~cm}^{-1}, 1581.77 \mathrm{~cm}^{-1}$, $1467.96 \mathrm{~cm}^{-1}, 1342.58 \mathrm{~cm}^{-1}, 1294.35 \mathrm{~cm}^{-1} 968.35$ and $482.25 \mathrm{~cm}^{-1}$ fully confirms the formation of PEO: PANI: $\mathrm{NaClO}_{4}$ composites.

Fig. 2(a) shows scanning electronic micrograph (SEM) image of pure polyethylene which is highly macro crystalline elongated rod like structure and has considerable intragranular distance between the two grains. It is clearly seen from the image that the PEO grains have less interaction with each other. The average grain size was calculated by using the linear intercept formula and it was found to be 345 to $400 \mu \mathrm{m}$.

Fig. 2(b) shows the higher resolution SEM image of pure PANI and was found to be mesoporous and highly agglomerated granular in shape and has amorphous nature. The average grain size was found to be 170 to $230 \mathrm{~nm}$. The grains are well interconnected with each other which indicate that they have enough binding energy to combine with neighbor grains or molecules. Fig. 2(c) shows SEM images of PEO: PANI composites which are highly agglomerated chain like structures. The crystallinity of the PEO decreases with the addition of PANI in it. The average grain size is found to be $350 \mathrm{~nm}$ to $400 \mathrm{~nm}$. Fig. 2(d) shows the SEM image of pristine sodium chlorate $\left(\mathrm{NaClO}_{4}\right)$ crystals which are ellipsoidal like structure and agglomerated to each other. The average grain size is found to be 35 to $40 \mathrm{~nm}$. Fig. 2(e) shows that PEO:PANI: $\mathrm{NaClO}_{4}$ (50:20:30) composites are found to be highly clustered, spherical in shape and have interlinked to each other which decreases the intragranular distance. The decrease in the intragranular between the grains helps the charge transfer mechanism from one grain to another grain. The average grain size is found to be $270 \mathrm{~nm}$.

Fig. 2(f) shows that the PEO: PANI: $\mathrm{NaClO}_{4}(50: 10: 40)$ composites which are highly crystalline has greater porosity than PEO: PANI: $\mathrm{NaClO}_{4}(50: 20: 30)$ composites and this clearly indicates that grains have less binding force with each other. The average grain size is found to be 2 to 4 $\mu \mathrm{m}$. Thus from Fig. 2(a) to 2(f) it was found that there is significant change in the morphology of various weight percentages of $\mathrm{NaClO}_{4}$ in PEO: PANI matrix's i.e. from ellipsoidal to square like morphology.
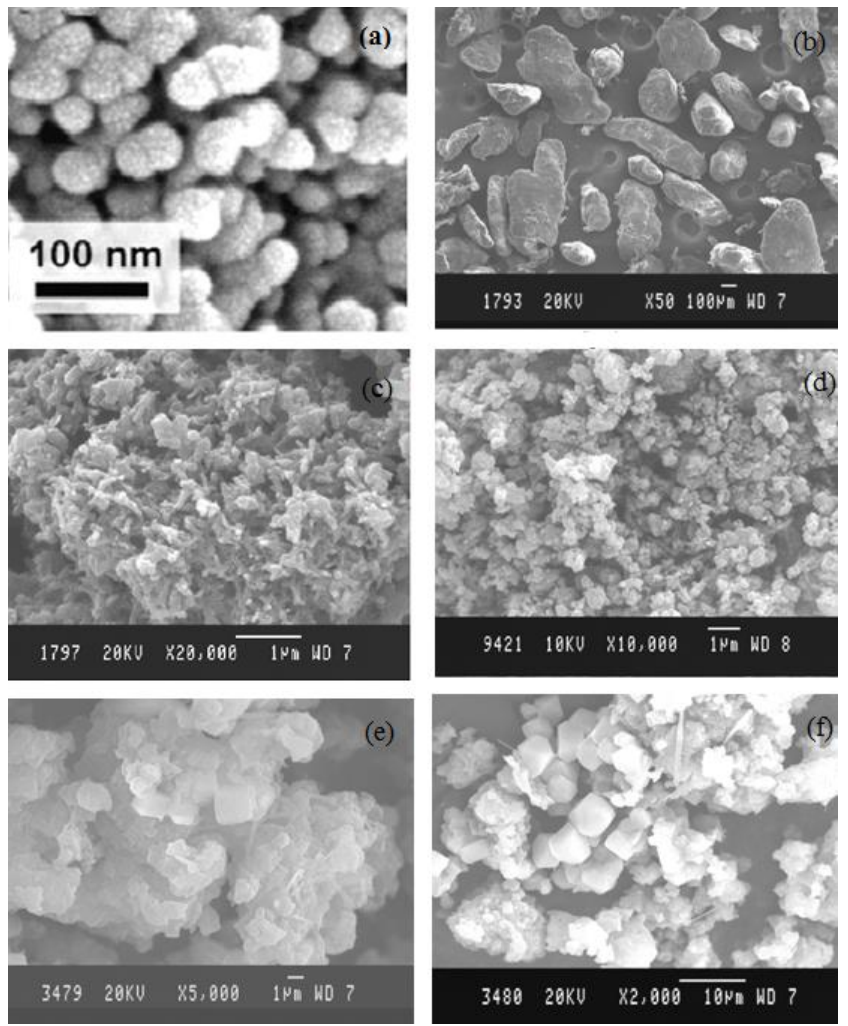

Fig. 2. SEM image of (a) PEO (b) PANI (c) PEO:PANI (d) $\mathrm{NaClO}_{4}$ (e) PEO: PANI: $\mathrm{NaClO}_{4}$ (50:20:30) (f) PEO: PANI: $\mathrm{NaClO}_{4}(50: 10: 40)$.

\section{AC conductivity}

Fig. 3 (a) shows $\sigma_{\text {ac }}$ versus frequency for different weight percentages of $\mathrm{NaClO}_{4}$ in PEO: PANI matrix. It is observed that the conductivity is found to increase with increase in frequency for all weight percentages. The composites PP5, N3 (PEO: PANI: $\mathrm{NaClO}_{4}(50: 20: 30)$ ), N4 (PEO: PANI: $\mathrm{NaClO}_{4}$ (50:10:40)) shows good conductivity 
which is due to ionic polarization and electrode polarization. Among all these composites N3 shows higher conductivity which is well understood from SEM studies. PP5 shows more conductivity than all the other composites except N3 because when PANI mixed with PEO gives more feasibility of matrix's for fast mobility of ions through it easily. The PEO, PN5, N1 and N2 show low conductivity due to dipole polarization which hinders the fast mobility of ions through the matrix [28].

Fig. 3 (b) shows $\sigma_{\mathrm{ac}}$ versus different weight percentages of $\mathrm{NaClO}_{4}$ in PEO: PANI matrix at various frequencies at $10 \mathrm{kHz}, 100 \mathrm{kHz}$ and $1000 \mathrm{kHz}$. It is observed that conductivity increases from PEO to PP5 and then suddenly falls down to N1. Again it increases from N1 to N3 and decreases to PN5. The highest conductivity is observed at $\mathrm{N} 3$ for $1000 \mathrm{kHz}$ when compared to other frequencies. This may be due to variable hopping of charge carriers and fast mobility of ions through the back bone polymer chain.
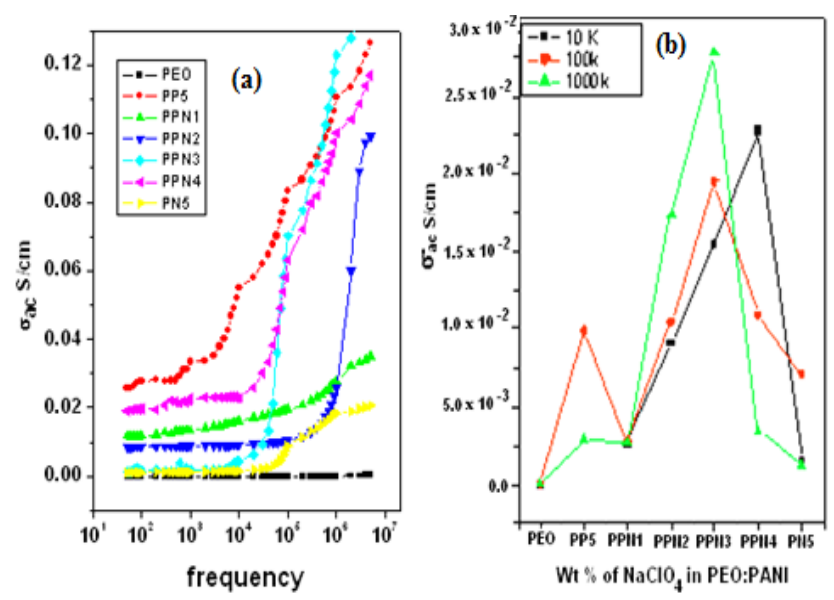

Fig. 3. (a) $\sigma_{\mathrm{ac}}$ conductivity verses frequency for different weight percentage of $\mathrm{NaClO}_{4}$ in PEO: PANI matrix.
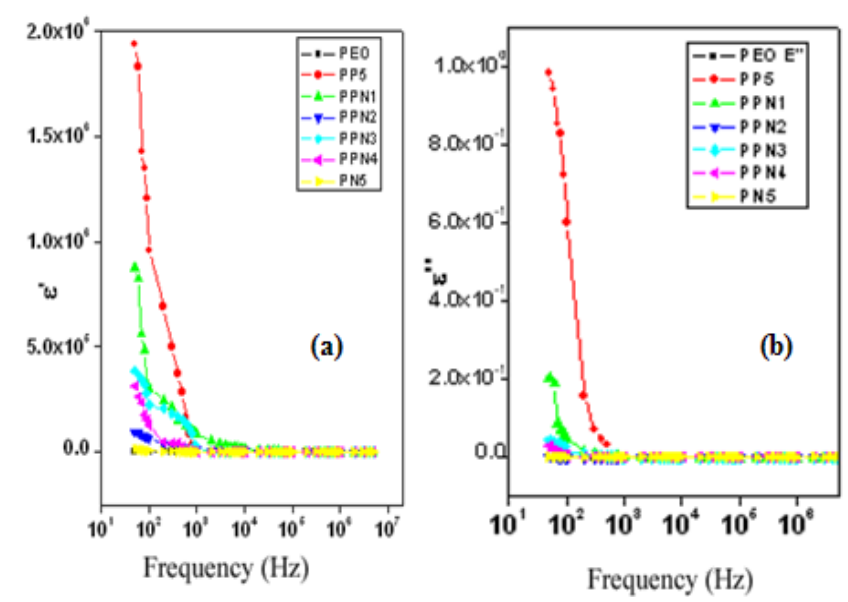

Fig. 4. (a) Variation of dielectric constant $\left(\sigma^{\prime}\right)$ with frequency for different wt\% of $\mathrm{NaClO}_{4}$ in PEO: PANI matrix.

Fig. 4 (a) shows the variation of dielectric constant $\sigma^{\prime}$ verses frequency for different $\mathrm{wt} \%$ of $\mathrm{NaClO}_{4}$ in PEO: PANI matrix. In all the cases a strong frequency dispersion of permittivity is observed in the low frequency region followed by a nearly frequency independent behavior above $1 \mathrm{kHz}$. The decrease of $\sigma^{\prime}$ with increase in frequency may be attributed to the electrical relaxation processes. The ionic and dipole polarization superimposed with each other and relaxation processes at lower frequencies. It is seen that with the addition of $\mathrm{NaClO}_{4}, \sigma^{\prime}$ value increases in the lower frequency and remains constant in the higher frequency region. The $\mathrm{NaClO}_{4}$ addition may result in fast moving of ions and more localization of charge carriers along with polarons causing higher ac conductivity. This may be the reason for higher $\sigma^{\prime}$ and strong low frequency dispersion on addition of $\mathrm{NaClO}_{4}$ in PEO: PANI matrix.

Fig. 4 (b) shows the variation of imaginary part of dielectric constant $\sigma$ " verses frequency for different wt $\%$ of $\mathrm{NaClO}_{4}$ in PEO: PANI matrix. At room temperature $\sigma "$ decreases with increasing frequency. The higher value of imaginary part of dielectric $\sigma$ " at low frequency is due to the freely moving of ions within the complex. On adding of $\mathrm{NaClO}_{4}$ in PEO: PANI matrix the imaginary part dielectric permittivity $\sigma$ " remains almost constant at over higher frequency range. It is observed that $\sigma^{\prime \prime}$ dielectric constant is maximum for $\mathrm{N} 3$ composites and remains constant for all the others. This confirms the enhancement of mobility of ions in the composites and is due to $\mathrm{NaClO}_{4}$ in PEO: PANI matrix.

Fig. 5 and 6 shows electrochemical cells that have been fabricated based on PEO:PANI:NaClO ${ }_{4}$ polymer electrolytes and their discharge curves determine under a constant load.

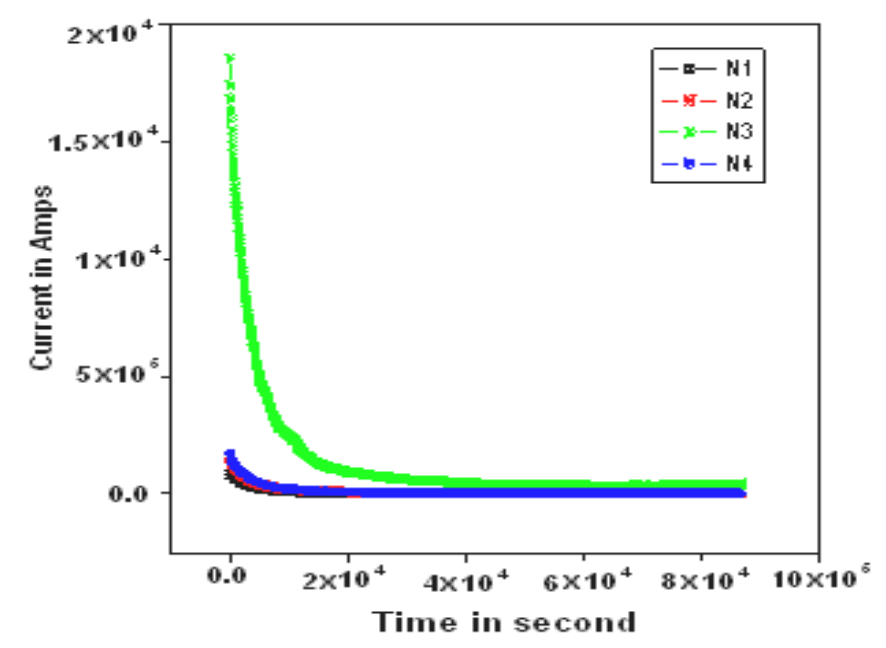

Fig. 5. Current verses time for PEO: PANI: $\mathrm{NaClO}_{4}$ composites.

There is an initial rapid decrease in polarization current as a function of time and that may due to the formation of a thin layer of sodium chlorate salt at the electrode or electrode interface. This suggests that the charge transport in PEO: PANI: $\mathrm{NaClO}_{4}$ composite is predominantly ionic. This indicates that PEO:PANI: $\mathrm{NaClO}_{4}$ composites have an electrochemical stability and are thus suitable for application in solid state batteries. As the PANI content increases in PEO there is an increase in the polarization current and in the voltage stability. With addition of more than $40 \% \mathrm{NaClO}_{4}$ in PEO: PANI matrix shows gradually decrease in the stability. The cell parameters results in an 
open-circuit voltage (OCV) of $1.2 \mathrm{~V}$ and a short circuit current (SCC) of 902uA for PEO:PANI: $\mathrm{NaClO}_{4}(50: 20: 30)$ composite. These data demonstrate the potential application of these electrolytes in solid state batteries. This may be confirmed by characterization and conductivity studies. The above results suggest that the charge transport in these composites is predominantly due to ions. Thus findings from the present study of PEO/PANI composites these composites are one of good candidates for sold state batteries.

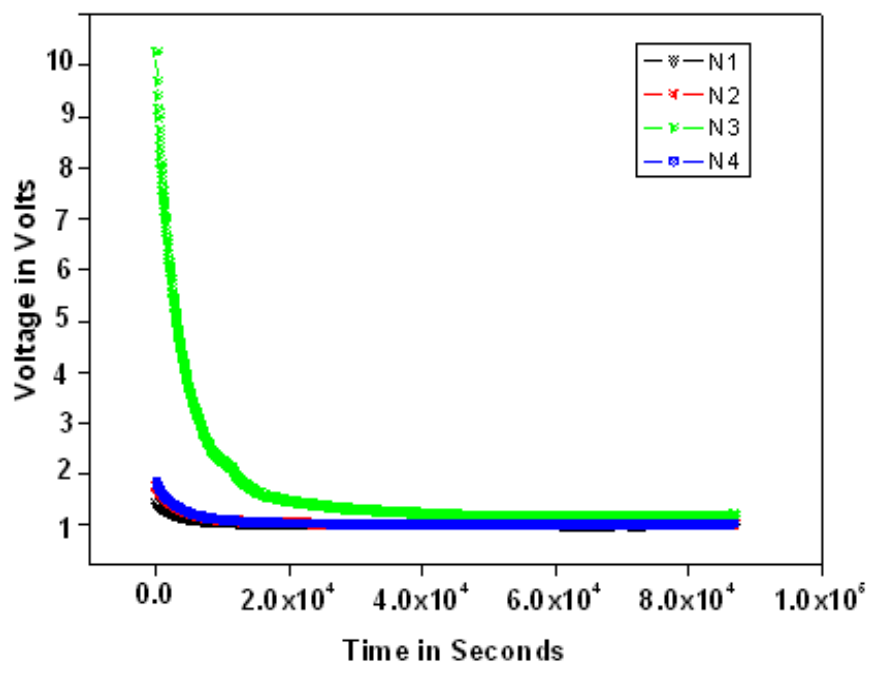

Fig. 6. Voltage verses time for PEO: PANI: $\mathrm{NaClO}_{4}$ composites.

\section{Conclusion}

The polymer electrolyte based on poly (ethylene oxide) complexed with conducting polyaniline and salt of sodium chlorate has been prepared in different weight percentage ratios. The complexation is confirmed by FTIR spectroscopy. The change in morphology of these composites was studied by employing SEM. The ac conductivity measurements are carried out by using LCR Q meter at room temperature. The composites PP5, N3 (PEO: PANI: $\left.\mathrm{NaClO}_{4} \quad(50: 20: 30)\right), \quad \mathrm{N} 4 \quad$ (PEO:PANI:NaClO 4 (50:10:40)) shows good conductivity which is due to ionic polarization and electrode polarization. Among all these composites N3 shows higher conductivity which is well understood from SEM studies. PP5 shows more conductivity than the other composites except N3 because when PANI mixed with PEO gives more feasibility of matrix's for fast mobility of ions through it easily. The variation of imaginary part of dielectric constant $\sigma^{\prime \prime}$ decreases with increasing frequency. The higher value of imaginary part of dielectric $\sigma$ " at lower frequency is due to the freely moving of ions within the complex. On adding of $\mathrm{NaClO}_{4}$ in PEO: PANI matrix the imaginary part dielectric permittivity $\sigma$ " remains almost constant at over higher frequency range. The variation of imaginary part of dielectric constant $\sigma$ " is maximum for N3 composites and remains constant for others. This confirms the enhancement of mobility of ions in the composites due to $\mathrm{NaClO}_{4}$ in PEO: PANI matrix. The formation of a thin layer of sodium chlorate salt at the electrode or electrode interface suggests that the charge transport in PEO:PANI:NaClO composite is predominantly ionic. This indicates that PEO: PANI: $\mathrm{NaClO}_{4}$ composites have an electrochemical stability and are thus suitable for application in solid state batteries. As the PANI content increases in PEO there is an increase in the polarization current and in the voltage stability.

\section{Reference}

1. M.A.Ratner, D.F.Shriver, Chem. Rev. 1988, 88, 109. DOI: $\underline{10.1021 / \mathrm{cr} 00083 \mathrm{a} 006}$

2. M.Armand, Polymer Electrolytes Ann. Rev. Mater. Sci. 1986, 16, 254. DOI: 10.1146/annurev.ms.16.080186.001333

3. Appetecchi G B, Hassoum J, Scrosati B, Croce F, Cassel F and Salomon M J. Power Sources 2003, 124, 246 DOI: $10.1016 / \mathrm{S} 0378-7753(03) 00611-6$

4. A. Tiwari, V. Singh, Carbohydrate Polymers 2008, 74, 427 DOI: 10.1016/j.carbpol.2008.03.015

A. Tiwari, Y. Sharma, S. Hattori, D. Terada, Ashok K. Sharma, A.P.F. Turner, H. Kobayashi, Biopolymers, 2013, 99, 334.

S. K. Shukla, Vamakshi, Minakshi, A. Bharadavaja, A. Shekhar, A. Tiwari, Advanced Materials Letters, 2012, 3, 421.

R.P. Singh, A. Tiwari, A.C. Pandey, J Inorg Organomet Polym, 2011, 21,788

S.K. Shukla, A. Tiwari, Advanced Materials Research, 2011, 306-307, 82 .

S. K. Shukla, A. Bharadvaj, A. Tiwari, G. K. Parashar, G. C. Dubey, Adv Mat Lett, 2010, 1, 129.

A. Tiwari, S. Gong, Talanta, 2009, 77, 1217.

A. Tiwari, S. Gong, Electroanalysis, 2008, 20, 1775.

A. Tiwari, Journal of Macromolecular Science Part-A: Pure and Applied Chemistry, 2007, 44, 735.

A. Tiwari, V. Singh, Express Polymer Letters, 2007, 1, 308.

A. Tiwari, J Polym Res, 2008, 15, 337.

A. Tiwari, S.P. Singh, J Appl Polym Sci, 2008, 108, 1169.

5. M.B.Armand, in: J.R.Mac Callum, C.A.Vincent (Eds), Polymer Electrolytes Reviews, 1987, 6, 22.

DOI: $10.1002 / \mathrm{pi} .4980200325$

6. E. A. Reitman, Kaplan.M.I., R.J. Cava, Solid State ionics. 1985, 17, 67.

DOI: 0 167-2738/85/\$03.30

7. A. Tiwari1, V. Sen, S. R. Dhakate, A. P. Mishra, V. Singh, Polym. Adv. Technol., 2008, 19, 909.

DOI: $10.1002 /$ pat. 1058

8. C. D. Robitaille and D. Fauteux, J. Electrochem. Soc. 133, 315 (1986) DOI: $10.1149 / 1.2108569$

9. K. Hanai, K. Kusagawa, M. Ueno, T. Kobayashi, N. Imanishi, A. Hirano, Y. Takeda, O. Yamamoto, (2010) J. Power Sources 195:2956. DOI: $10.1016 /$ j.jpowsour.2009.08.087

10. M.Shreekant, J.Reddy, L.Narasaih, U.V.Subba Rao, (1995) Mater. Sci. Eng. 33:173. DOI: SSD1 0921-5107(94)01206-0

11. Kunteppa H, Aashis S. Roy, Devendrappa H, M. V. N. Ambika Prasad, (2012) Journal of Applied Polymer Science, 2012,125, 1652. DOI: $10.1002 /$ app.34825

12. B.B. Owens, W.H. Smyrl, J.J. Xu, J. Power Sources. 1999, 81, 150 DOI: $\underline{\text { O0378- } 775398.00208-0}$

13. M. Winter, J.O. Besenhard, M.E. Spahr, P. Novak, Adv. Mater. 1998, 10,725 .

DOI: $10.1002 /($ SICI) 1521-4095(199807)10:10

14. Garima Mishra, A. K. Srivastava, Journal of Macromolecular Science, Part A: Pure and Applied Chemistry, 2007, 44, 747. DOI: $10.1080 / 10601320701353173$

15. Ashutosh Tiwari, Shaoqin Gonga, Electroanalysis, 2008, 20, 1775. DOI: $10.1002 /$ elan.200804237

16. S. Passerini, J.J. Ressler, D.B. Le, B.B. Owens, W.H. Smyrl, Electrochim. Acta, 1999, 44, 2209.

DOI: S00 1 3- 468 6( 98 )0 03 4 6- 6

17. B.B. Owens, S. Passerini, W.H. Smyrl, Electrochim. Acta. 1999, 45, 215.

DOI: S00 13 3- 4686 (99)0 020 5- 4

18. J.J. Xu, A.J. Kinser, B.B. Owens, W.H. Smyrl, Electrochem. Solid State Lett. 1998, 1,1

DOI: $\underline{\text { S1099-0062(97)11-069-0 }}$

19. Ameena Parveen, Koppalkar R. Anilkumar, Shantala D. Patil and 
Aashis S. Roy, Ionics, 2012, 19, 91.

DOI: $10.1007 / \mathrm{s} 11581-012-0719-7$

20. F. Leroux, G. Goward, W.P. Power, L.F. Nazar, J. Electrochem. Soc. 1997, 144, 3886.

DOI: $10.1021 / \mathrm{cm} 0110268$

21. J. Harreld, H.P. Wong, B.C. Dave, B. Dunn, L.F. Nazar, (1998) J. Non-Cryst. Solid A. 225: 319.

DOI: S0022-3093_98.00321-4

22. H.P. Wong, B.C. Dave, F. Leroux, J. Harreld, B. Dunn, L.F. Nazar, (1998) J. Mater. Chem. 8:1019. DOI: $10.1039 / \mathrm{A} 706614 \mathrm{G}$

23. H. Kunteppa, Aashis.S.Roy, A. R. Koppalkar, M. V. N. Ambika Prasad, Physica. B, 2010, 406, 3997.

DOI: $10.1016 /$ j.physb.2010.11.074

24. Jeong Hun Seo, Jonghyun Park, Gregory Plett, and Ann Marie Sastry, Electrochemical and Solid-State Letters, 2010, 13, 135.

DOI: $1099-0062 / 2010 / 13-9 / A 135 / 3 / \$ 28.00$

25. K. Naresh kumar, T. Sreekanth, M. Jaipal Reddy, U. V. Subba Rao, (2001) J. Power Sources 101:130.

DOI: S0378-7753 (01) 00658-9

26. A .R. Koppalkar, A. Parveen, G. R. Badiger and M.V.N.Ambika Prasad, Physica B. 2009, 404, 1664.

DOI: $10.1016 /$ j.physb.2009.01.046

27. D. Rajendra, A. S. Roy, A. Parveen, Composites: Part B, 2013, 52, 211.

DOI: $10.1016 /$ j.compositesb.2013.04.004

\section{Advanced Materials Letters}

\section{Publish your article in this journal}

ADVANCED MATERIALS Letters is an international journal published quarterly. The journal is intended to provide top-quality peer-reviewed research papers in the fascinating field of materials science particularly in the area of structure, synthesis and processing, characterization, advanced-state properties, and applications of materials. All articles are indexed on various databases including DOAJ and are available for download for free. The manuscript management system is completely electronic and has fast and fair peer-review process. The journal includes review articles, research articles, notes, letter to editor and short communications. 